\title{
One Philosophical Dialogue: (Mutual) Understanding and the Art of Reticence
}

\author{
Svetlana Rudanovskaya \\ Department of Social Philosophy \\ Faculty of Humanities and Social Sciences \\ Peoples' Friendship University of Russia \\ Miklukho-Maklay str., 10/2, Moscow, Russia, 117198 \\ E-mail: rudsv@live.ru
}

\begin{abstract}
The idea of philosophical dialogue centers on the idea of a thought-out conversation between interlocutors who are interested in clarifying the concepts and foundations of knowledge. In M. Heidegger's A Dialogue on Language: Between a Japanese and an Inquirer participants are supposed to avoid ready-made definitions of culture while approaching the original wonder of thought in its contact with an undefined world. This experience is revealed and interpreted during the dialogue in connection and in tune with the Japanese art of reticence and understatement. The article deals with the concept of dialogue as a non-classical conversation which refrains from the accepted procedures of knowledge production, pays attention to language, returns to the origins of philosophical inquiring. Emphasis is made on a process of understanding as "paving a path"; that is deliberate, keen to signs, differences, unpredictable in its discoveries, and far from being finished.
\end{abstract}

Keywords-philosophical dialogue; language of dialogue; indefiniteness; Japanese art; differences; translation; understanding; existence; path of though; M. Heidegger

\section{INTRODUCTION}

There are dialogues which tend to create problems; there are dialogues which are supposed to solve problems. Since Socrates' time a philosophical dialogue has been designed to deal with problems and provide the participants with the opportunity to brood over new layers of human existence. The dialogue reveals the cognitive and communicative capacities of interlocutors, their abilities to find links between different spheres of reality, the extent of their responsiveness to questions and criticism of each other ${ }^{1}$. The dialogue' aim is the comprehension of the universally significant meanings of being against the background of the world mentally liberated from the personal interests, conventions, undoubted limits. Instead of interpersonal competition or satisfying personal ambitions, a community of philosophers is "a special type of humanity, living in finitude but oriented toward poles of infinity" $[8 . \text { P. 160] }]^{2}$.

\footnotetext{
${ }^{1}$ For more details about dialogical thinking, see M. Buber's work [5. P.114] ${ }^{2}$ Various aspects of transcendence in the past and nowadays have been detailed in F.V. Tagirov's "Transcendent: Reality or "Invention of Thought" [18].
}

A dynamic dialogical form implies a clash of ideas, variety of standpoints, unpredictable movement of thought. Initially this form corresponds to the philosophical ideals of non-dogmatic thinking ${ }^{3}$. The dialogue is incompatible with declarative affirmations, as well as empty talks on everything. It creates an intellectual environment for a disciplined thought that clarifies concepts and fights against a cognitive emptiness of the words taken for granted. As a text written and directed by a particular author, the dialogue represents an ideal space without problematic social interactions, destructive conflicts, waste or lack of time. Within the dialogue it's impossible to dream or talk away; the dialogue sharpens the participants' attention, makes everybody speak to the point. The philosophical conversation is likely to take place in a "friendly" confiding atmosphere, protected from aliens, those who pursue their own benefit or don't recognize the significance of the talk. The space of philosophical dialogue is similar to the utopian territory: there are no traces of estrangement or compulsion, inequality of start positions, policy of interests; everything bears the stamp of enlightened reason that can rebuff and overcome the shallow, premature remarks and also enlighten the consciousness, "address the better self of a human being" [13. P. 53]. However this space has its limits in time, suggests a singular event. Unlike utopia, a dialogue is a self-organizing reality that exists as long as an intellectual "feast", intensive search for the most important things in life keeps on going [10. P. 99-108].

"A Dialogue on Language: Between a Japanese and an Inquirer" appears in the middle of XX century, when the idea of a dialogue starts to be in the center of literary studies, philosophical hermeneutics, critical theory and social anthropology. The phenomenon of dialogue suggests the novel existential and social opportunities, though the dialogue as a form of philosophical text hasn't become widespread $^{4}$. M. Heidegger's dialogue fills the shortage of this kind, but represents both an example of ideal interaction,

\footnotetext{
${ }^{3}$ Non-dogmatic character of a dialogue is emphasized in the following works: [19], [23]. ${ }^{4}$ In the XX much attention is paid to philosophy of dialogue [11], [13], as
well as to ideal models of dialogical situations which enable to reach deliberate agreement [24].
} 
based on coordinated search for philosophical meanings, and an example of resistance to standard cognitive techniques of exploring speculative areas. The conversation begins with recollections about count Kuki, who used to attend an Inquirer's lectures and was a Japanese's teacher. Those personal relations naturally imply continuity of ideas, sharing the same scope of interests, giving and receiving knowledge despite cultural distances. Simultaneously the figure of the Japanese professor represents not only a mediatory link between participants, but embodies a special attitude towards formal side of scientific discourse. Together with reference to count Kuki, the interlocutors introduce the topic of shallow conversation and profound silence. "A man may speak, speak endlessly, and all the time say nothing. Another man may remain silent, not speak at all and yet, without speaking, say a great deal. People can talk much without saying anything, and they can say a lot of things, without pronouncing a word" [21. P. 122]. Count Kuki with his preference to refrain from specially organized discussion grows into paradigmatic figure that sets the direction of the dialogue, focuses it on the possibilities and limits of the natural language as well as possibilities and limits of the dialogue itself.

\section{NON-Classical Dialogue}

Since Antiquity a philosophical dialogue hasn't admitted indefinite statements which are common for day-to-day talk. A classical dialogue combats ignorance, indifference towards the truth submitted by deep-skin unfounded judgments. In contrast to the classical conversation, M. Heidegger's dialogue points out to the danger of well-defined truth, "super-definiteness" or unconscious attachments to definitions which encourage the thought to take the "wellworn tracks of traditional thinking" [21. P. 36]. The main intention of a philosophical conversation (in M. Heidegger's interpretation) is to overcome the circular motion of thought in the space of rhetorical figures, consistent sentences distanced from the fundamentals of being; the end of the dialogue is to liberate the consciousness from long-held assumptions interfering with the process of exploring complicated reality as it is. On the one hand, it doesn't differ much from the classical dialogue where the energetic core of the conversation consists in opposition between "the authentic" and "the unauthentic", a thought directed to "the things themselves" and a thought "riding on the surface" in the sphere of popular views. On the other hand, there's the difference.

The classical dialogue by Plato longs to reveal the true knowledge which cancels all previous questions and presumptions and allows the seekers to be satisfied with their search. The truth can be caught through language. As A. Lose puts it, "while the chosen theme growing, the voices become stronger and more confident. Then Socrates' voice outmatched them and makes everybody listen to it with reverence. Nevertheless it turned out that Socrates himself only echoes another voice, that is the one of a wise priestess Diotima" [10. P. 100]. The motive of climbing, progressive approach to the truth becomes the prevailing plot of a classical dialogue; it's the motion from obscure images to unclouded vision of reality, and the possibility of this vision is due to intellectual accuracy and insight ${ }^{5 \cdot}$ As far as $M$. Heidegger's dialogue is concerned, the vision of reality is the peak of the dialogue too, but this vision is not final and guaranteed, but flickering and discontinuous. Moreover it's possible due to the fact that there can be some loopholes, "gaps", "hints" in naturalized sign system (with predictable replicated combinations of elements), and those hints open up "an abundance to think of" [21. P.15]. The dialogue, according to M. Heidegger's interpretation, doesn't try to get the way to a reasonable observer's privileged position, but turns to the "non-privileged" position of ignorance as a result of intellectual emancipation from speculative form of knowledge. Those who are in search of the truth find themselves in a situation when strategy of questions and answers doesn't help them to understand the most important things in the human existence. It's indispensable to find the proper language for formulating the questions which won't multiply "simulacra" or impersonal general concepts. The motive of the quest for this language in the dialogue intertwines with the motive of "wayfaring", characterized by uncertainty, halts, the necessity to choose the path by trial and error.

Strictly speaking there are no "inquirers", nor those who are "sophisticated in answers". Both participants are thinkers who didn't accept the theoretically elaborated frame of knowledge. They do know the diversity of language, its "traps" and opportunities, and they are experienced in interpretation of complex texts. Simultaneously they have no "objective" knowledge, that is they have no stockproduced instruments of cognition, and they refrain deliberately from systematic, conceptualized reflection of reality. The mainstream intellectual mood of the dialogue is prudence in speech, which are similar to the care of travelers who enter an unbeaten tracks, or to put it another way, who starts to talk about human existence afresh (as if all the previous history of interpretation wasn't at hand). The key to the existential understanding is a particular use of words: "I: How is one to give a name to what he is still searching for? To assign the naming word is, after all, what constitutes finding" [21. P. 20]. Mutual support in continuing this search is no less important: "I: This is what our language calls "hesitate." It is done truly when slowness rests on shy reverence. And so I do not wish to disturb your hesitation by urging you on too rashly. J: You are more helpful to me in my attempt to say the word than you can know. [21. P. 28]. Interlocutors focus on the words which express the conceivable reality ${ }^{6}$, but at the same time make attempts to touch the reality that "speaks" itself, give the floor to the unobvious Other" ${ }^{7}$. Therefore there's a strong demand to

\footnotetext{
${ }^{5}$ There are some exceptions here. Referring to the earlier Plato's dialogues, A.V. Nazarchuk states that sometimes they ended with "defeat of all its participants" (including Socrates) that nevertheless followed by "intellectual catharsis". [13. P. 55].

${ }^{6}$ For more details about phenomenological experience of self-cognition, see E. Kurmeleva's "Believing Reality" [9. P. 192].

${ }^{7}$ As this reality is akin to thought, open to human being, indispensable from historical language. Comments to this idea see in [22] as well as a detailed analysis of Heidegger's dialogue in the context of definitions and etymology of dialogue in general.
} 
discover this Other beyond and among the words spoken and read, to be ultimately attentive to the meanings of language they use.

\section{UNDERSTATEMENT AND UNDERSTANDING}

The dialogue represents the art of speaking about human existence without converting it into alienated verbal patterns. The approach like this meets the requirements of Japanese aesthetic principles of reticence, understatement. According to these principles the artist outlines the shapes of prelinguistic, pre-human reality - changeable and fluid - which can't be caught with final forms. This art helps everybody interested in it see the world full of wonderful mystery of ontological presence. A line, a gesture, a hint in communicating the meaning are those mingy manifestations of being that allow the audience "to admire the invisible" [14. P. 43], guess rhythms and a spirit of life as it is (without artificial superstructures). The artist "self-withdraws", "following a movement of brush, the spirit of creation", "words", "the call of things" [6. P. 167] In this case the language is perceived as something "secondary, suited only for pointing to the truth, not for expressing it" [17].

Like the art of reticence, M. Heidegger's dialogue isn't motivated by pursuit of knowledge, agreement, original expression (something that hasn't come into being yet), but driven by the possibility of getting in contact with things that exists latently and can be cancelled by informative, "instrumental" language. The dialogue is supposed to reveal the reality that is constantly omitted behind the definite terms, standard maps of vision, one-sided explanations. The dialogue's goal is to recognize those aspects of reality that are always at hand, but ignored by the mind which is under the influence of abstract blueprints of being. However, instead of direct experience of reality (similar to the aesthetic experience in the Japanese tradition), the dialogue introduces the idea of gradual approach to the "untold" meanings unclaimed in the process of knowledge production. "The untold" is interpreted as an indispensable feature of language (not a property of a singular masterpiece), and this language is seen as another interlocutor who should "be allowed to talk", manifest itself with the help of other participants. "The untold" should become "told" at the level of hermeneutically unfolded language that combines poetic responsiveness with the will to be evident: "Say" means to show, to let appear, to let be seen and heard" [21. P. 122].

The feeling of understatement engenders the search for the best statement, as this statement influences the extent of intensity and clarity of one's own being. Discovering the right words equals to the event, an individual expression obtains the ontological meaning and importance. The danger of the dialogue in this case consists in choosing the words which lead to nowhere (in contrast to hints), miss the point, make inquirers wander among accepted linguistic clichés. It is those clichés that don't let people "see" and "hear", join in the experience of authentic existence in its wholeness.

If there's some "self-withdrawing" in the dialogue, it doesn't occur at the cost of the subject's peculiarities, but rather at the cost of objective disinterested attitude to reality, the language that affirms distances and outlines borders between objective and subjective, sensible and supersensible properties. Nevertheless with all difficulty of choosing the right words for representing the authentic experience of existence, the language of the dialogue is ultimately precise. There is no lexical indefiniteness arisen from the artificial encoding of the words or destruction of linguistic structures. The language of the dialogue is descriptive, biographical now and then, helpful in reconstructing tracks of lives and their junctions. This language delineates equally well both social events (meetings, discussions, lectures, publication of the works) and mental activities (events of understanding ideas, texts, cultural phenomena).

First of all, the conversation brings to light the differences between European and Japanese cognitive styles (in aesthetic perception of pieces of arts). Both interlocutors are in consonance that the precision of European languages bears undercurrent inaccuracy in relation to other cultures; the meanings of other cultures' phenomena are constantly eliminated under the influence of European classifications, being embedded in unnatural frames empowered upon them. Understanding of the "superseding", generalizing character of discursive language brings about a ceaseless mutual clarifying the terms used in conversation, liberates differences which are likely to be disappeared without attention. Interlocutors and, first of all, an Inquirer, are interested in the non-alienated presence of the other, for in this situation it's much easier to correct one's own expansive intentions or naive miscomprehension ${ }^{8}$.

The non-European Other supports and supplements an Inquirer as the latter intends to overcome cultural (metaphysical) determinants; a Japanese notices and grasps intuitive guesses that are getting out of his companion's sight. Right from the start the Other understands an Inquirer, his intentions, since both share the practice of translation and interpretation the same texts. A Japanese is a professor on German literature who knows and admires Hölderlin, having translated an Inquirer's lectures on Hölderlin into the Japanese language [20. P. 277]. Despite the fact that there's some danger that one's own frame of reference will invisibly replace the original with subsequent pseudo-dialogue ${ }^{9}$, the translation opens the way to revitalizing the translated text, placing it in another living space behind the limits of local language [2]. As a translator, a Japanese tends to be a "mirror reflection" of an Inquirer with his particular attitude towards existence restricted by an "objective" language. The only chance to release those restricted possibilities is to develop the special attitude towards language, paying attention to "open" word (a hint), getting away from a mechanical translation that conceals the original meanings of reality. The translation (as a "journey" among cultures) overcomes the power of language habits and generates the

\footnotetext{
${ }^{8}$ Though the tendency to substitute "the other" by "one's own" properties appears in the case of dialogical, "colloquial" proximity of concepts, for example, "indefinite" and "ineffable", "emptiness" and "being" (the latter misunderstanding is analyzed in [17]).

${ }^{9} \mathrm{~K}$. Yu. Solonin explains the proximity between ideas of M. Heidegger and D. Sudzuki by a translation effect, as the latter's works were translated into German with the consideration of M. Heidegger's vocabulary. [17].
} 
feelings of non-postulated, non-imposing "kinship" between differences, an attracting power of a wonderful concord, unexpected coincidence. A Japanese confesses: “And while I was translating, I often felt as though I were wandering back and forth between two different language realities, such that at moments a radiance shone on me which let me sense that the wellspring of reality from which those two fundamentally different languages arise was the same" [21. P. 24] Then he makes a remark: "As far as I am able to follow what you are saying, I sense a deeply concealed kinship with our thinking precisely because your path of thinking and its language are so wholly other" [21. P. 40-41].

A conversation between a Japanese and an Inquirer is a model and event of an "understanding" (hermeneutic) attitude towards existence in general. Despite the differences some universal properties of cultures are being detected during the conversation; though it's impossible to reveal them by gradual generalizations or structural analysis. Those properties are connected with such existential themes as vital search, expectation, choice of one's own way of life (slipping away, unguaranteed, inevitable). In a Japanese culture "to understand" means to perceive everything in constant movement ("an art of sensing the North Star in the Southern sky" [6. P. 173]), in the passage to another state, in the flow of life, independent from human desires. In the context of the dialogue "to understand" means to reexperience the awareness of human presence in the world (the universal experience that is familiar to all thinking creatures), see the various progressions, prior to any static statements. The understanding of this kind bears a cultural originality and at the same is in tune with the way of understanding born in another culture. "I: Petals that stem from Koto. [A Japanese image for language]. Imagination would like to roam away into still unexperienced realms when this word begins its saying [Heidegger's indication to the essence of language]" [21. P.48]. "To understand" means "to exist in relations": to follow the meanings imbedded in language, to listen to the Other, to discover "a conversation", "bearing" [21. P. 19] in silence, and a possibility of a real conversation, where a human being is transformed into a "messenger" [21. P. 54], in common talk.

\section{CONCLUSION}

A dialogue between a Japanese and an Inquirer doesn't solve cognitive or social problems, but draws the human attention to the reality which is being lost among the amount of informational messages, short- or long-term projects, formal communications. The art of "hinting" in a Japanese culture is a way to the natural "vastness" of the world, where one can contemplate phenomena existing in their rusticity. A dialogical hint is a way to the "vastness" which is contrary to the narrow constructions of thought, concepts taken for granted. Everything can be a hint - a text, a dialogue, other philosophical systems, a word. Simultaneously everything may be talked out and left alone, solved, put aside to other things, in the archive of personal and social history. To detect "hints" is to liberate the thought from its reified character, a will "to capture" and control the environment [15. P. 293-294]; while following the hints, one allows the world to exist in the image and likeness of creation which speaks and awaits human appreciation. This process reminds a tiny motion in the Noh play which exists in the space of understanding and says much to those who is mentally open to receive a message [20. P. 283]. In this case there's an inner dialogue, without an actual conversation with the Other. The most important thing is that in its search of understanding the Other, a thought travels through the areas of recognized "ideas" and "things" into the spheres free from "noise of language", showy ideologies, powerful intentions. Into the spheres of tranquility and emergence of meanings, where a philosophical inquiring is possible, as well as a feeling of belonging to the wonderful world, not yet explored and told about.

Being a kind of "microcosmos", M. Heidegger's dialogue is "open in time and space" thought which is not predestined or arbitrary (neither is any interpretation of text or piece of art), but requires some human efforts to choose this path and keep following it with awareness of one's going and passing. The choice of a meaningful path by looking backwards to the beginnings is a peculiarity of the dialogue between a Japanese and an Inquirer. This look embraces the start of acquaintance and friendship, genesis of ideas, fundamentals of language, understanding/misunderstanding. It's usual to turn back to something that was once missed, left, in order to reconstruct mentally the continuity of movement, the agreement between "far" and "near" things, "initial" and "following". Understanding doesn't refer to contemplation of the world in transit but to the ability to gather and guard one's own world, which otherwise would be shattered (under the influence of abstract language) into informational files, units, images. And in this world, gathered and cared about, it's easier to distinguish various quests by different others, who besides their standard social roles, explore the limits and indefiniteness of the whole world, including their individual path.

The dialogue activates the awareness of participants' presence in the world as those who are alert and ready to set off (contrary to those who are deaf and satisfied in their status quo), who approaches to the moments of insight, bearing in mind the essential incompleteness of this process. To exist, as well as to participate in a dialogue, implies being at work of disclosing, collecting, co-creating the paths, building the meaningful living space that is open for investigation: "I: Thinking is fond of a manner of a road building that is, I would almost say, wondrous. J: A manner in which the builders must at times return to construction sites they left behind, or go back even further" [21. P. 21] $]^{11}$.

\footnotetext{
${ }^{10}$ About a poetical form of tanka which is "open in time and space" see in V. Markova's "Introduction" to "Classical Japanese Poetry" [12. P. 13] ${ }^{11}$ Analyzing M. Heidegger's ideas of "path" and "space", V. A. Podoroga refers to the idea of building: "There are modes of human existence on earth - to build, live, think» [15. P. 291]. Usually "building" is associated with a planned construction and mathematical calculation. But in this particular case "to build" means "to pave the path" among multiple possibilities, risks of meeting a dead-end and risks of sticking somewhere once and for all. That's why the process of building doesn't refer to accomplishment of this or that singular project, but to the idea of
} 


\section{REFERENCES}

[1] Bibikhin V.V. The case of Heidegger // Heidegger M. Time and Being: articles and speeches. M.: Respublica, 1993. pp. 3-14.

[2] Bibikhin V.V. On the Meaning of Translation. URL: http://bibikhin.ru/k_probleme_opredeleniya_sushnosti_perevoda (12.02.2016).

[3] Bibikhin V.V. Substitution Translation. URL: http://bibikhin.ru/podstsnovochnyi_perevod (12.02.2016).

[4] Bibikhin V.V. Heidegger. URL: http://bibikhin.ru/haydegger (12.02.2016).

[5] Buber M. Dialogue // M. Buber Two images of faith. Translated by I.M. Levina. M.: Respublika, 1995. pp. 93-124.

[6] Grigorieva T. P. The movement of Beauty. Notes on a Japanese Culture. M.: "Vostochnaya Literatura" RAN, 2005. 440 p.

[7] Hussel E. Philosophy and the Crisis of European Man // E. Husserl Philosophy as a Rigorous Science. Novocherkassk: Agenstvo Saguna, 1994. pp. 101-126.

[8] Husserl E. Philosophy and the Crisis of European Man // E. Husserl Phenomenology and the Crisis of Philosophy. Translated by Q. Lauer. N.Y.: Harper Torchbook, 1965. pp. 149-192.

[9] Kurmeleva E.M. Believing Reality // Bulletin of Peoples' Friendship University of Russia. Series 'Philosophy'. M., 2002. №3. pp. 190-196.

[10] Losev A. F.., Takho-Godi A.A. Plato. Aristotle. M.: Molodaya Gvardiya, 1993. 383 p.

[11] Maiboroda D.V. Dialogism // History of Philosophy: Encyclopedia. Minsk.: Interpressservis; Knijnii Dom. 2002. pp.317-318.

[12] Markova V. Introduction // Classical Japanese Poetry. M.: AST, 2008. pp. 5-34.

[13] Nazarchuk A.V. Philosophical understanding of a dialogue in the light of communicative approach // Bulletin of Moscow State University. Series 7. Philosophy. M., 2010. №1. pp. 51-71.

[14] Ovchinnikov V. Branch of Sakura. M.: Molodaya gvardiya, 1971. $224 \mathrm{p}$.

[15] Podoroga V.A. Metaphysics of landscape. Communicative strategies in philosophical culture of XIX-XX centuries. M.: Canon-Plus, 2013. $552 \mathrm{p}$.

[16] Pomerants G. Dialogue // Cultural studies. XX century. Encyclopedia. Vol. 1. Ed. by S.Ya. Levit. SPb.: Universitetskaya kniga, OOO "Aleteiay".

http://yanko.lib.ru/books/cultur/cul turology20century2volumes1998sl .htm (16.02.2016).

[17] Solonin K.Yu. Heidegger and Japanese philosophy // Heidegger and the Eastern philosophy. Eds. By M.Ya. Korneev, E.A. Torchinov. The 2nd edition. SPb.: Sankt-Peterburgskoe philosophskoe obschestvo, 2001. URL: http://knigosite.org/library/read/69903 (12.02.2016).

[18] Tagirov F.V. Transcendent: Reality or "Invention of Thought" // Bulletin of Peoples' Friendship University of Russia. Series 'Philosophy'. M., 2008. №1. pp. 40-44.

[19] Philosophical dialogue // Philosophic Encyclopedic Dictionary. M.: Sovetskaya encyclopediya, 1983. p. 740.

[20] Heidegger M. Time and Being: articles and speeches: Translation from German to Russian by V.V. Bibihin. M.: Respublika, 1993. 447 p.

[21] Heidegger M. On the Way to Language. Translated by Peter D. Hertz. N.Y., L.: Harper and Row Publishers, 1971. 200 p.

[22] Rockwell G. The Danger of Dialogue // Rockwell G. Defining Dialogue: From Socrates to the Internet, Amherst, New York: Humanity Books (an imprint of Prometheus Books), 2003. URL: http://www.geoffreyrockwell.com/publications/Defining.Dialogue.Ch .2.pdf (14.02.2016).

meaningful movement, that requires the same intellectual concentration and the same responsiveness as in a dialogical space.
[23] Rowe S. Dialogue as Hope and Vocation // Soundings: An Interdisciplinary Journal, v. 89, N1/2 (Spring/ Summer), 2006. URL: http:// www.jstore.org/stable/41179146 (2.02.2016).

[24] Walzer M. A Critique of Philosophical Conversation // The Philosophical Forum. N.Y., 1989/1990. V.XXI, Nos. 1-2. pp. 182-196. 